\title{
O impresso movimento da UNE e o debate sobre a alfabetização no Brasil
}

\section{The magazine movimento from UNE and the debate about literacy in Brazil}

Carla Michele Ramos Torres ${ }^{1}$

Maria Isabel Moura Nascimento ${ }^{2}$

\section{Resumo}

Durante os anos iniciais da década de 1960 a União Nacional dos Estudantes (UNE), enquanto força progressista, atuou no cenário político brasileiro em prol de reformas estruturais que promoveriam o desenvolvimento nacional e a emancipação econômica do país. Nesse contexto a entidade universitária produziu a revista Movimento, procurando divulgar as principais ideias da intelectualidade progressista e, consequentemente, politizar a massa estudantil sobre a realidade nacional. A fim de trazer à tona um dos temas mais abordados no impresso, este artigo objetiva examinar como a questão da alfabetização foi expressa nas páginas do periódico, edições de 1962 e 1963. Por meio do referencial teórico-metodológico do materialismo histórico dialético buscamos identificar qual era o entendimento da UNE sobre o problema do analfabetismo e a relação entre essa forma de consciência e as condições históricas do Brasil naquele período. Observamos que a temática teve destaque na revista por fazer parte das principais mobilizações estudantis na época, uma vez que a alfabetização era uma das condições fundamentais para a consolidação da democracia e do progresso da nação, segundo o pensamento progressista.

\footnotetext{
${ }^{1}$ Docente de História do Instituto Federal do Paraná - Campus Irati. Doutora em Educação pela Universidade Estadual de Ponta Grossa. Pesquisadora do Grupo Histedbr-Campos Gerais. E-mail: carla.ramos@ifpr.edu.br.

2 Docente do Programa de Pós-Graduação em Educação da UEPG, PR. Doutora em Educação pela UNICAMP - SP. Coordenadora do Grupo HISTEDBR - Campos Gerais. Professora Produtividade CNPq. E-mail: misabelnasc@gmail.com.
}

Interfaces da Educ., Paranaíba, v.10, n.28, p.77 à 101, 2019

ISSN 2177-7691 


\section{8}

O impresso movimento da UNE...

Palavras-chave: União Nacional dos Estudantes. Imprensa Estudantil. Revista Movimento. Alfabetização.

\section{Abstract}

During the early 1960's the National Union of Students (UNE in the Portuguese acronym), as a progressive movement, acted in the Brazilian political scenario in favor of structural reforms that would provide national development and the economic emancipation of the country. In this context, UNE produced the Magazine Movimento aiming to spread the main ideas of progressive intellectuals and, consequently make students politically aware about the national reality. In order to discuss one of the most approached themes in the magazine, this article aims to examine how literacy was expressed in the aforementioned magazine in its 1962 and 1963 editions. The theoretical-methodological framework used to identify the understanding held by UNE about illiteracy and the relationship between this form of awareness and the historical conditions of Brazil in the period was based on the materialist historical-dialectical approach. The theme was frequently discussed in the magazine because it was part of students' main mobilizations at the time and because according to the progressive thinking, literacy was essential for the consolidation of democracy and the progress of the nation.

Keywords: National Union of Students. Student Press. Magazine Movimento. Literacy.

\section{Introdução}

O Brasil, nos primeiros anos da década de 1960, vivenciou uma série de transformações nas relações capitalistas de produção, na organização politica e cultural e no âmbito social. Essas mudanças colaboraram na consolidação de uma forma de pensamento intitulado como progressista, uma vez que as contradições daquele contexto histórico demandavam um posicionamento político-econômico em defesa de um projeto de nação que atendesse as novas configurações sociais. 


\section{9}

Carla Michele Ramos Torres e Maria Isabel Moura Nascimento

Nessa conjuntura a União Nacional dos Estudantes (UNE), enquanto setor progressista, procurou politizar as massas populares, em especial o público universitário, sobre os problemas do país e as lutas a serem enfrentadas em prol da sua emancipação. Assim, em 1962 a entidade universitária reeditou a revista Movimento para ser um canal oficial do pensamento intelectual progressista brasileiro. (EDITORIAL, 1962).

Um dos principais temas, relacionados à educação brasileira, abordado nas páginas da revista Movimento (edições de 1962 e 1963), foi o analfabetismo. Essa questão estava sendo debatida por diferentes setores da sociedade, uma vez que, em 1961, foi aprovada a primeira Lei de Diretrizes e Bases da Educação $\mathrm{Nacional}^{3}$. Logo, enquanto entidade política representativa dos estudantes do mais alto nível educacional brasileiro, a UNE não poderia ficar alheia a essas problemáticas e passou a disseminar seu projeto educacional para a massa estudantil.

Nesse contexto de debate em torno de uma legislação educacional, ocorreu a formação de diversos movimentos de educação e cultura popular. As Campanhas de Alfabetização ${ }^{4}$ vinham crescendo ao longo dos anos de 1950 na tentativa de diminuir os altos índices de analfabetismo entre crianças e adultos. Além dessas campanhas, no início da década de 1960, surgiram experiências regionais com a proposta de elevar o nível cultural e a consciência politica das camadas populares, como, por exemplo o Movimento de Cultura

\footnotetext{
${ }^{3}$ A tramitação do projeto da LDB foi iniciada em 1948 e finalizada por meio da Lei 4.024, de 20 de dezembro de 1961. Foram treze anos de tramitação o que "[...] evidencia a lentidão de um Legislativo em debater e aprovar temas de grande importância e complexidade, notadamente os de interesse social, e que se destinavam à regulamentação de matérias constitucionais." (LOMBARDI, 2016, p. 31).

${ }^{4}$ Entre as campanhas governamentais de alfabetização, criadas entre 1945 e fins de 1950 , destacamos a "Campanha Nacional de Educação de Adolescentes e Adultos" que implantou uma rede de escolas supletivas; a "Campanha Nacional de Educação Rural" voltada especificamente para a população rural; a "Mobilização Nacional de Erradicação do Analfabetismo"; o "Sistema Rádio Educativo Nacional" com a implantação de escolas radiofônicas.
} 


\section{0}

O impresso movimento da UNE...

Popular5 $^{(\mathrm{MCP}), \text { Movimento de Educação de Base }}{ }^{6}$ (MEB) e os Centros Populares de Cultura (CPC) ${ }^{7}$.

Essa movimentação para melhorar os índices educacionais e culturais do país partiu de iniciativas coletivas eclesiásticas e estudantis, de artistas e intelectuais, algumas apoiadas pelos governos locais e até mesmo pelo governo federal. A democracia, apesar de algumas disfunções ${ }^{8}$, e a organização oriunda da crescente industrialização e urbanização colaborou na construção de um espaço propício para a realização de projetos de educação popular, algo que acabava incomodando setores econômicos e políticos hegemônicos, partidários de uma estrutura social conservadora e tradicional fundada no passado colonial. (PRADO JÚNIOR, 1981).

No caso do movimento estudantil, o CPC da UNE colaborou para que a experiência de cultura para o povo fosse implementada em diversos estados brasileiros. A revista Movimento da UNE publicou que essa seria a "[...] primeira experiência brasileira de arte para as grandes massas, reunindo, junto à UNE, estudantes, intelectuais e artistas num trabalho de autêntica elaboração cultural." (CPC da UNE, 1962, contracapa). Segundo os idealizadores do projeto, a cultura deveria atuar para emancipar o povo brasileiro, promovendo artes visuais, teatro, música e cinema a fim de politizar o público estudantil em geral, os operários e os camponeses sobre os problemas brasileiros, engrossando a luta pelas transformações defendidas pelos setores progressistas.

Tanto a cultura quanto a educação popular foram pensadas pelos setores progressistas como uma ação fundamental para o desenvolvimento

\footnotetext{
5 O MCP surgiu em 1961, na cidade de Recife, durante a gestão do prefeito Miguel Arraes. Criado por artistas e intelectuais, esse movimento criou espaços educativos e culturais para crianças e adultos pobres e analfabetos, além de ter sediado a primeira experiência do sistema Paulo Freire.

${ }^{6}$ O MEB foi criado em 1961 pela Conferência Nacional dos Bispos do Brasil e apoiado pelo governo federal. Sua proposta consistia na alfabetização e na educação de base voltada para conscientização das camadas populares.

${ }^{7}$ Os Centros Populares de Cultura nasceram da experiência do CPC da UNE, entidade criada em 1961 no Rio de Janeiro, por iniciativa de artistas, intelectuais e estudantes universitários, com o propósito de conscientização política das massas populares.

8 No período entre 1945 e 1964, apesar dos governos democraticamente eleitos, tivemos alguns episódios como a morte de Getúlio Vargas e a renúncia de Jânio Quadros que acabaram criando instabilidade politica.
} 


\section{1}

Carla Michele Ramos Torres e Maria Isabel Moura Nascimento

nacional, pois como um país pretendia ser autônomo no mercado mundial com uma carência de educação profissional e tecnológica? Ou como seria possivel a promoção de um Estado Democrático Popular capaz de realizar reformas politicas para eliminar o imperialismo e o latifúndio, se boa parte da população não conseguia o direito de voto por ser analfabeta? Ou como aumentar a produção interna de bens diante das disparidades econômicas? Enfim, como a educação poderia corroborar para extirpar o subdesenvolvimento?

No caso da alfabetização, o assunto foi expresso nas páginas do Movimento a fim de politizar os universitários, especialmente as lideranças que representavam o público leitor em potencial, sobre o problema do analfabetismo, bem como mobilizar o movimento estudantil para a realização de campanhas de alfabetização em massa. Assim, o periódico ao mesmo tempo que expressou uma visão de sociedade, também procurou intervir naquela realidade como instrumento de militância política.

\section{Alfabetização: frente de luta pelo desenvolvimento nacional}

Sabemos que a educação teve, e ainda tem, um papel significativo nos diversos projetos de nação existentes durante a história da República Brasileira e de maneira singular:

\footnotetext{
Pelo menos até 1970 as políticas públicas para a educação sempre foram revestidas de uma forte motivação centralizadora, associada a discursos de 'construção nacional' e a propostas de fortalecimento do Estado. Discursos abrangentes que sustentavam propostas de reformas na economia e na política, e para as quais a educação da população brasileira era considerada patamar fundamental. (SHIROMA; MORAES; EVANGELISTA, 2000, p. 13).
}

A realidade material do Brasil já não era mais a mesma do início do século XX, pois com a intensificação da indústria e, consequentemente, o desenvolvimento das forças produtivas e do mercado interno, bem como o processo crescente de urbanização, as relações produtivas, socias, políticas e culturais demandavam uma organização educacional que desse conta dessas novas configurações. Para que o país caminhasse rumo ao desenvolvimento, 


\section{2}

O impresso movimento da UNE...

era preciso que a educação atendesse aos ideais de um progresso econômico nacional que consistia resumidamente na:

[...] ampliação e renovação das técnicas, transformação nas fontes de energia, alterações no comércio exterior, desenvolvimento da produção industrial, preponderância do mercado interno, ampliação do mercado de trabalho, intercorrência de conflitos externos, estruturação de uma economia nacional, luta contra as fôrças econômicas imperialistas. (SODRÉ, 1963, p. 112).

Uma circunstância concreta no Brasil, nesse periodo, era a alta taxa de analfabetismo, sendo que os maiores indices estavam presentes na população feminina e na zona rural. Em 1950, por exemplo, 51,65\% das pessoas não sabiam ler e nem escrever (IBGE, 1955), fato que demonstra o paradoxo entre o direito jurídico institucional e a realidade concreta no modo de produção capitalista, já que o acesso à educação era garantido na forma da lei pela Constituição de 1946.

Apesar do percentual de analfabetismo ter diminuído para 39,7\% em 1960, na faixa da população de 15 anos ou mais (INEP, [200?]), o fato era que mais de um terço dos brasileiros não possuía um dos elementos mais importantes para o acesso ao conhecimento científico, além de estarem excluídos da participação política para a escolha dos representantes do Legislativo e Executivo do país. Essa última situação fragilizava a própria democracia, ou seja, o terreno de luta adotado pelos setores progressistas partidários do desenvolvimento nacional.

A UNE, como setor progressista, se movimentou no cenário político brasileiro e voltou suas atenções para as questões educacionais, empregando sua revista Movimento para interpretá-las junto ao público universitário. Além disso, a intenção da entidade era que Movimento colaborasse na "[...] elaboração de uma consciência geral e unânime dos problemas dos universitários brasileiros", pois “[...] os problemas dos universitários brasileiros são os problemas da sociedade brasileira.” (MOVIMENTO, 1962, p. 2).

O tema do analfabetismo no Brasil foi abordado na segunda edição da revista Movimento da UNE pelo estudante de engenharia da Universidade do 


\section{3}

Brasil e também coordenador do Movimento Popular de Alfabetização (MPA) da entidade universitária, Arond Abend. O título da matéria, "O Grande País dos Analfabetos", procurou enfatizar essa situação como um enorme problema existente no país e sua abordagem inicial também anunciava a principal perspectiva política que os dirigentes estudantis possuíam em relação a essa questão. As primeiras informações do artigo apresentavam dados de 1960 da população geral, da população analfabeta e dos eleitores, respectivamente.

Brasil.

1960.

65,3 milhões de habitantes.

33 milhões maiores de 18 anos.

15,5 milhões de eleitores inscritos.

12,5 milhões de votantes.

Pelo menos 50\% da população maior de 18 anos não votou porque é analfabeta. (ABEND, 1962, p. 5).

Os dados acerca da população brasileira foram apresentados de forma fracionada, primeiramente a quantidade total de habitantes e depois a parcela maior de 18 anos, justamente para abordar o número de eleitores e votantes. A exposição finalizou-se com a principal questão abordada no decorrer da matéria, ou seja, o alto índice de não eleitores devido ao analfabetismo presente entre esses indivíduos. Como coordenador do MPA, o universitário Arond Abend discutiu o problema do ponto de vista econômico e políticoideológico, mas se concentrou nesse último aspecto.

Concluímos então que os 15 milhões de analfabetos maiores de 18 anos constituem uma realidade politica a nos demonstrar que existem condições concretas de, sob o ângulo do analfabetismo, travar-se uma importante batalha, que seria a isenção dêstes milhões de brasileiros no processo eleitoral. (ABEND, 1962, p. 5).

A luta, portanto, deveria focar a eliminação do analfabetismo a fim de promover a elevação do número de eleitores, permitindo a ampliação da democracia e dos interesses das camadas mais populares. Essa alternativa foi a solução encontrada pelas forças progressistas que se envolveram nos movimentos de educação e cultura popular, visto que a opção do voto ao analfabeto não teria sucesso por depender de uma reforma constitucional, de 


\section{4}

O impresso movimento da UNE...

uma profunda mobilização popular e de apoio de grupos sociais privilegiados economicamente, condições essas muito distantes da realidade nacional. (ABEND, 1962).

A opção da UNE pela campanha de alfabetização e não pelo voto ao analfabeto estava conectada ao contexto de mobilizações da educação e cultura popular que vinham crescendo em várias regiões do país, no início de 1960. As lideranças universitárias acreditavam que esse movimento:

Ensinaria a ler e escrever. Incutiria hábitos culturais. Assim abriria um enorme caminho para a participação politica e ideológica de milhões de brasileiros, pois ganhariam a oportunidade de se tornarem eleitores e impulsionados pela própria realidade objetiva teriam os meios elementares necessários para acelerar a elevação do nivel de consciência crítica. (ABEND, 1962, p. 5).

Além da influência dos movimentos de educação e cultura popular em nível nacional, a UNE também foi estimulada a mobilizar o movimento estudantil em campanhas de alfabetização, tendo como exemplo o processo revolucionário cubano e as realizações do governo de Fidel Castro na área educacional. Vale ressaltar que a Revolução Cubana era enaltecida pelo movimento estudantil como exemplo de luta anti-imperialista na América e sua vitória em 1959 estimulou ainda mais o combate contra o imperialismo, em especial a dominação estadunidense.

Em 1963, a revista Movimento publicou uma reportagem sobre o II Congresso de Conselhos Municipais de Educação de Cuba, evento ocorrido em Havana, capital da ilha cubana. Nessa matéria o autor descreveu várias conquistas educacionais e, no que diz respeito à alfabetização, destacou:

Em 1961, 'Ano da Educação', Cuba reduziu sua percentagem de analfabetismo à cifra ínfima de $3,9 \%$ graças à mobilização popular que levou milhares de jovens e adultos a ensinar a ler e escrever a seus irmãos do campo e da cidade.

Essa tarefa não se deteve aí imediatamente - uma vez vencida a batalha contra o analfabetismo - foram criados cursos de PostAlfabetização (de 'Seguimiento') para que os recém-alfabetizados não limitassem suas conquistas a saber ler e escrever. (CABRERA, 1963, p. 42). 


\section{5}

Carla Michele Ramos Torres e Maria Isabel Moura Nascimento

Outra experiência ressaltada por Cabrera (1963) foi a proposta de educação popular em Cuba que consistiu na oferta de ensino para operários e camponeses em seus espaços de trabalho (fábricas, granjas, empresas e oficinas), a fim de que esses trabalhadores alcançassem uma escolaridade equivalente ao sexto ano primário. Essas ações, no campo educacional cubano, foram divulgadas aos leitores do periódico Movimento em comunhão com o pensamento progressista que procurava veicular os avanços educacionais como desdobramento da vitória anti-imperialista.

No campo das mobilizações de educação e cultura popular, as condições nacionais levaram a UNE a escolher o caminho político-ideológico, pois acreditava que, na superestrutura da sociedade, poderiam ser realizadas ações que tivessem repercussão na estrutura econômica. Ou seja, a campanha de alfabetização liderada pelos universitários promoveria efeitos práticos que colaboraria na transformação da organização produtiva brasileira.

Embora esse pensamento exaltasse uma atuação no campo da superestrutura, o posicionamento de Arond Abend enfatizou que o triunfo da campanha de alfabetização dependeria de outros fatores socias que não foram citados em sua matéria e sim num outro artigo de autoria da própria UNE, conforme visualizamos a seguir.

\footnotetext{
Cem mil universitários podem ser mobilizados para esta campanha, desde que, de fato as autoridades federais superem as pressões do latifúndio e setores externos. Cem mil universitários podem se oferecer para um trabalho com que pagariam, apenas em parte, o privilégio de terem atingido o ensino superior no Brasil analfabeto. Tôdas as uniões estaduais dos estudantes, estamos certos, poderiam desde já organizar suas comissões em grupos de trabalho, em vista de uma campanha como esta, realmente demonstrativa da maturidade do movimento estudantil. (UNE, 1962b, p. 13, grifo nosso).
}

A revista Movimento disseminou a ideia que a erradicação do analfabetismo brasileiro só seria possível com intensa mobilização social. Além disso, a UNE apresentava uma campanha que dispensava esquemas oficiais estreitos e alienantes, bem como uma relação paternalista diante dos trabalhadores urbanos e rurais. (UNE, 1962b). Assumindo a posição de 


\section{6}

O impresso movimento da UNE...

indivíduos privilegiados, os dirigentes universitários se colocaram à disposição para sensibilizar a opinião pública para esse problema nacional, porém, a própria entidade apontou o papel político das autoridades federais como fator decisivo para tal empreitada. Assim, o pensamento progressista confiava ao poder público uma ação que não era capaz de realizar.

Além do ensino da leitura e da escrita, o MPA da UNE procurava também politizar as camadas populares para que pudessem tomar partido nas mobilizações sociais em curso no país. O sentido da educação popular já não era mais a implantação das escolas primárias que se viu durante os movimentos da Primeira República e nem somente a ampliação da rede pública na época de tramitação do projeto da primeira LDB.

A mobilização que toma vulto na primeira metade dos anos de 1960 assume outra significação. Em seu centro emerge a preocupação com a participação política das massas a partir da tomada de consciência da realidade brasileira. E a educação passa a ser vista como instrumento de conscientização. A expressão "educação popular" assume, então, o sentido de uma educação do povo, pelo povo e para o povo, pretendendo-se superar o sentido anterior, criticado como sendo uma educação das elites, dos grupos dirigentes e dominantes, para o povo, visando a controlá-lo, manipulá-lo, ajustá-lo à ordem existente. (SAVIANI, 2007, p. 315).

Para os setores progressistas, a ideologia do desenvolvimento nacional decorreria da consciência das massas populares, “[...] a) porque são elas que executam as tarefas materiais do desenvolvimento; b) porque êste é feito em proveito delas.” (VIEIRA PINTO, 1960, p. 136). Dessa maneira, era preciso que aqueles que representavam a maior força de trabalho tivessem acesso a uma educação que pudesse abrir caminhos de transformação social. A politização das camadas populares foi defendida como fator imprescindivel por intelectuais brasileiros que fundamentavam teoricamente as ações da UNE, como foi o caso de Álvaro Vieira Pinto, disseminador das seguintes teses:

[...] sem ideologia do desenvolvimento não há desenvolvimento nacional $[. .$.$] a ideologia do desenvolvimento tem necessariamente de$ ser fenômeno de massa [...] o processo de desenvolvimento é função da consciência das massas [...] a ideologia do desenvolvimento tem de proceder da consciência das massas. (VIEIRA PINTO, 1959, p. 32-38). 


\section{7}

Carla Michele Ramos Torres e Maria Isabel Moura Nascimento

Orientada por essas ideias, a UNE procurou justificar em seu periódico Movimento que as agremiações estudantis se encontravam numa posição mais privilegiada para realizar a campanha de alfabetização e atrair a adesão popular. Primeiramente, por causa da sua tradição de luta pelas questões nacionais; segundo, por estarem restituindo parte dos privilégios que possuiam enquanto universitários; e, finalmente, por serem membros das camadas médias, gozando de prestígio popular. (ABEND, 1962).

A concepção de vanguarda universitária apresentada nas páginas do Movimento tinha a intenção de sensibilizar a base estudantil para que se envolvesse nas ações de alfabetização, nesse sentido:

A imprensa representa, talvez, o mais edificante meio de formação de opinião pública: é com base no que os jornais publicam que milhões de pessoas raciocinam, apreendem e aprendem, formando juízo sôbre tudo partindo das informações divulgadas. (BARRETO, 1963, p. 6).

A questão do analfabetismo para a UNE e outros setores progressistas estava diretamente vinculada com o princípio liberal democrático de ampliação da participação política e na constituição de um Estado representativo da maioria populacional. Pois, na sociedade brasileira, "sob o prisma do analfabetismo situam-se cêrca de 30 milhões. Dêstes, perto de 15 milhões são considerados incapazes politicamente. Não votam. São analfabetos." (ABEND, 1962, p. 5).

Como somente os alfabetizados poderiam ser eleitos e eleger seus representantes políticos, uma parcela considerável da sociedade ficava alheia ao processo eleitoral. Nesse sentido, para a UNE, a elevada taxa de analfabetismo no Brasil era um entrave à democracia, impossibilitando a ascensão de um Estado Democrático Popular, capaz de promover as reformas defendidas pela ideologia do desenvolvimento nacional. Como a luta dos setores progressistas contra o poder hegemônico imperialista e latifundiário era pela via política, essa defasagem eleitoral prejudicava a tomada de poder pelo caminho da legalidade. 


\section{8}

O impresso movimento da UNE...

Para entender a opção pela via política e ideológica da UNE, precisamos retomar o princípio liberal disseminador da ideia de que o poder legislativo, como árbitro da justiça, tem a função de unir os membros de uma sociedade, pois esse poder "[...] é o ato primeiro e fundamental da sociedade [...]" (LOCKE, [20--], p. 93) e foi estabelecido para elaborar as leis conforme a vontade da maioria. Influenciado, portanto, pela ideologia liberal dominante na sociedade brasileira naquela época, o pensamento progressista, presente na revista Movimento, afirmava que a solução para os problemas educacionais do país era a criação de “[...] um Estado democrático portanto popular.” (UNE,1962a, p. 4).

O Estado Democrático se diferenciava do modelo de governo predominante em nossa sociedade, assim apresentado na revista Movimento:

Vivemos de fato em um regime de estatismo liberal, considerando estatismo todo o regime em que o estado interfere de modo unilateral, instrumentando qualquer tipo de dominação quer de classes partidos ou organismos sobre a grande massa do povo, alienado do poder real de decidir sobre seu destino. (UNE,1962a, p. 4, grifo do autor).

Ao contrário dessa organização politica, o Estado Democrático Popular, sustentado pela ideologia do desenvolvimento nacional, seria a verdadeira representação popular e, dessa forma, não atenderia os interesses privados das classes dominantes. Porém, as publicações do impresso Movimento não aprofundaram a natureza do Estado, ou seja, a sua conexão com o modo de produção da sociedade e o fato de provir “[...] do processo de vida de indivíduos determinados [...]" (MARX; ENGELS, 2007, p. 93).

No modo de produção capitalista, o Estado existe para proteger a propriedade privada concentrada nas mãos dos proprietários dos meios de produção. O Estado é a forma que os burgueses encontraram para universalizar seu projeto econômico à sociedade em geral. No capitalismo, a democracia expressa igualdade e liberdade no campo da jurisprudência e não no campo da realidade concreta e, por isso, a manutenção de uma sociedade de classes é a preservação da desigualdade material entre os indivíduos. 


\section{9}

O pensamento progressista, veiculado na revista Movimento, considerou o Estado Liberal como o responsável pelo subdesenvolvimento e não avançou no sentido de compreender que a raiz do problema estaria na estrutura que o criou. Além disso, não compreendeu que o “[...] poder político, em seu sentido real, é o poder organizado de uma classe para a opressão da outra" (MARX; ENGELS, 2012, p. 69) e o poder público somente perde esse caráter político quando desaparecem as classes. Logo, a ideia de uma reforma educacional que atendesse as reais necessidades da classe trabalhadora, promovida por um Estado Democrático Popular, acabava sendo uma concepção invertida do real, incapaz de se consolidar no interior da sociedade de classes.

Além de fragilizar a democracia, o analfabetismo foi concebido pela UNE como um subproduto da organização produtiva brasileira, fundamentada no latifúndio e no imperialismo.

Ao latifúndio, o ensino é um investimento do capital sem nenhuma vantagem econômica e até perigosa do ponto de vista político. Ao imperialismo, o analfabetismo é uma forma de conservar o sistema de trabalho que pode manter vastas áreas do país no sistema précapitalista. (UNE, 1962b, p. 12).

No artigo "Realidade do Analfabetismo no Brasil”, publicado na edição especial de julho de 1962 da revista Movimento, a UNE denunciou o analfabetismo a partir da conjuntura econômica brasileira e, de forma especial, como uma instituição do latifúndio. Dessa maneira, o analfabetismo presente entre a classe trabalhadora atingia principalmente os trabalhadores rurais, pois para o sistema produtivo dominante, resistente ao fortalecimento da indústria nacional, o país não necessitava de muitas escolas, uma vez que "para tanger bois, manejar enxada não há necessidade de escola, pois a escola é a vida diária." (UNE, 1962b, p. 12).

Apesar da crescente urbanização, em 1960, o Brasil possuía 55\% da população concentrada na zona rural (IBGE, 1962) e eram raras as exceções 


\section{0}

O impresso movimento da UNE...

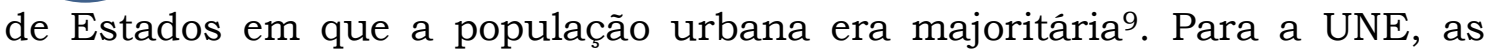
regiões rurais eram celeiros de analfabetos e semianalfabetos (UNE, 1962b) o que se confirma pelos dados apresentados no Quadro 1:

Quadro 1 - Matriculados e concluintes do ensino primário brasileiro em 1960

\begin{tabular}{|l|r|l|r|c|}
\hline \multicolumn{2}{|c|}{ Matrícula Geral } & \multicolumn{2}{c|}{ Conclusão } & Taxa de conclusão \\
\hline Urbano & 3.893 .000 & Urbano & 391.374 & $10,05 \%$ \\
\hline Distrital & 602.295 & Distrital & 41.764 & $6,93 \%$ \\
\hline & & & & $3,93 \%$ \\
\hline Rural & 2.962 .707 & Rural & 116.496 & $7,37 \%$ \\
\hline Total & $\mathbf{7 . 4 5 8 . 0 0 2}$ & Total & $\mathbf{5 4 9 . 6 3 4}$ & \\
\hline
\end{tabular}

Fonte: Anuário Estatístico do Brasil (IBGE,1962). Adaptado pela autora.

Conforme os dados do Quadro 1, o percentual de conclusão do ensino primário na zona rural, em 1960, era o menor percentual comparado com as regiões distrital e urbana. A taxa média de 4\% de conclusão demonstra a disparidade com outras regiões, apesar de o índice ser baixo em todas as áreas. Isso demonstra o distanciamento entre a legislação, que garantia ao cidadão o direito à educação, e a realidade educacional brasileira, em especial na região em que havia maior concentração de pessoas naquele período.

As novas configurações produtivas e sociais, a partir do crescimento industrial e do processo de urbanização, produziram mudanças na esfera educacional brasileira. A oferta do ensino primário, por exemplo, aumentou no decênio de 1950 a 1960, conforme o Quadro 2. Mas, em contrapartida, os indices de conclusão ainda eram muito baixos quando comparados ao número de matriculados.

Quadro 2 - Número de escolas, matrículas e conclusões do ensino primário no Brasil em 1950 e1960

\begin{tabular}{|l|r|r|r|}
\hline & $\mathbf{1 9 5 0}$ & \multicolumn{1}{|c|}{$\mathbf{1 9 6 0}$} & \multicolumn{1}{c|}{ Taxa de Crescimento } \\
\hline Unidades Escolares & 77.625 & 95.938 & $24 \%$ \\
\hline Matrículas & 5.240 .142 & 7.458 .002 & $42 \%$ \\
\hline Conclusões & 427.340 & 549.634 & $29 \%$ \\
\hline População Total & 51.944 .397 & 70.967 .185 & $37 \%$ \\
\hline
\end{tabular}

Fonte: Anuário Estatístico do Brasil (IBGE,1955 e 1962). Adaptado pela autora.

9 Segundo o Serviço Nacional de Recenseamento, em 1960, somente os Estados do Amapá, Rio de Janeiro, Guanabara, São Paulo e Distrito Federal possuiam a população urbana maior que a população rural. (IBGE, 1962). 


\section{1}

Carla Michele Ramos Torres e Maria Isabel Moura Nascimento

Um dado relevante para uma análise mais profunda dos impedimentos reais da alfabetização brasileira é o número de conclusões no ensino primário. Em 1950, observamos, por meio dos dados do Quadro 2, que somente 8,16\% dos estudantes matriculados nesse nivel de ensino conseguiram concluir seus estudos, e em 1960 o resultado decaiu para 7,37\%, revelando que o problema fundamental estava relacionado muito mais com a permanência do que ao acesso escolar.

As relações de trabalho e as condições de vida no campo, por exemplo, dificultavam o êxito das crianças nesse nível educacional, pois, apesar de $72,36 \%$ das instituições escolares primárias se concentrarem nas regiões rurais e $90 \%$ das unidades escolares brasileiras serem públicas ${ }^{10}$, nesse período, a taxa de conclusão na zona rural era de 3,93\% em 1960 (IBGE, 1962). Havia, portanto, uma contradição, pois tínhamos uma maior oferta de escolas primárias na zona rural, mas não possuíamos um elevado aproveitamento dessa oferta.

A realidade da educação nas zonas rurais levou a UNE a difundir em sua imprensa a existência de "[...] um primeiro impedimento de ordem material que se deve considerar" (UNE, 1962b, p. 12), ao analisar os baixos indices de aproveitamento escolar nessas regiões. Segundo a entidade universitária, as péssimas condições materiais alimentadas pelo sistema de latifúndio impediam a escolarização da classe trabalhadora e sua conscientização politica.

A estrutura latifundiária e monocultora do Brasil e as relações de trabalho nela existentes interferiam diretamente nas condições educacionais no campo, uma vez que essa realidade não exigia uma mão de obra tecnicamente capacitada e impedia a ascensão de pequenos proprietários. Além do mais, a ausência de uma legislação trabalhista subordinava os trabalhadores rurais aos proveitos dos proprietários e, para esses, a formação

10 As unidades escolares, em 1960, segundo a dependência administrativa, estavam organizadas da seguinte forma: Federais $(0,47 \%)$, Estaduais $(43,36 \%)$, Municipais $(46,51 \%)$, Particulares (9,66\%). (IBGE, 1962). 


\section{2}

O impresso movimento da UNE...

intelectual dos trabalhadores e dos seus filhos poderia gerar perturbações no sistema vigente e, por isso, a organização produtiva dificultava tanto a admissão nas escolas quanto a continuidade e finalização dos estudos.

No relatório apresentado na plenária do I Encontro Nacional de Alfabetização e Cultura Popular, realizado em setembro de 1963 na cidade de Recife, foi destacada a importância de campanhas de alfabetização na zona rural por ser a região mais povoada e por existirem as condições humanas mais precárias se comparadas às cidades. Segundo o documento:

[...] o camponês brasileiro, poucas vezes possui condições de vida humana. Ora dispersos na imensidão geográfica do país, ora superpopulando certas áreas, o camponês brasileiro é sempre vítima da exploração. Padece o homem do campo do Brasil, de um cortejo de males, todos eles interdependentes, podendo ser ressaltado o alarmante índice de analfabetismo e baixo nivel de consciência política, de capacitação tecnológica, etc. (COMISSÃO A, 2009, p. 283).

Além das condições materiais do campo, outros obstáculos eram apresentados à alfabetização e à politização dos trabalhadores rurais, como, por exemplo, a dificuldade de comunicação entre os alfabetizadores e os sujeitos a serem alfabetizados. Os movimentos de educação e cultura popular eram liderados por sujeitos letrados e culturalmente superiores aos analfabetos e, muitas vezes, a linguagem entre eles se tornava improdutiva devido às disparidades sociais e por esse motivo o "[...] trabalho de alfabetização deve, portanto, pautar-se de uma interação cada vez maior com o povo, deve procurar uma identificação tão completa quanto possivel com a comunidade onde atua [...]" (MEB, 2009, p. 312).

Para os setores progressistas, o analfabetismo era um dos mecanismos da manutenção de poder, tanto no campo quanto na cidade e, do ponto de vista econômico, foi apontado pelos dirigentes estudantis, na revista Movimento, como um elemento positivo para a organização latifundiária brasileira e para os interesses hegemônicos do capital estrangeiro, pois preservava essa estrutura produtiva. Assim,

o analfabetismo como efeito só será eliminado quando desaparecerem suas causas econômicas o que implica uma luta que se projeta desde 


\section{3}

sua base econômica até a politico-ideológica, envolvendo a sociedade em batalhas cruentas e incruentas, silenciosas e agitadas. (ABEND, 1962, p. 5).

Vimos que o caminho escolhido pela UNE foi a luta no campo político e ideológico, apesar de ter considerado o analfabetismo como efeito da base produtiva vigente e a importância de atacar a causa. Porém, conforme as próprias palavras do coordenador do MPA, o caminho pela via econômica envolveria a sociedade brasileira em campanhas violentas e essa opção não era a alternativa dominante entre os setores progressistas e até mesmo pelo Partido Comunista Brasileiro de grande influência ideológica nos movimentos políticos de esquerda, no início da década de 1960.

Vinícius Caldeira Brandt, presidente da UNE e integrante da Ação Popular, reafirmou o compromisso da entidade universitária em apoiar o processo eleitoral para o legislativo, em outubro de 1962, sem ater em atividades políticas partidárias, “[...] mas a um trabalho sôbre a democratização eleitoral [...]”. (BRANDT, 1962, p. 27). Essa postura disseminada no impresso Movimento vinha ao encontro com a posição assumida pela ala política da esquerda menos radical, aprovada pelos comunistas, em "[...] atribuir às eleições um papel importante na consecução de um govêrno nacionalista democrático [...]" (SILVA; CASTRO; GUIMARÃES, 1962, p. 5).

A luta pela ascensão das classes populares ao poder era a campanha dos setores progressistas e "[...] as eleições aparecem como válvula de escape institucional para evitar um desfêcho mais violento." (SILVA; CASTRO; GUIMARÃES, 1962, p. 3). As eleições expressavam, portanto, a via pacífica para a constituição de um governo comprometido na realização das reformas estruturais do projeto de desenvolvimento nacional e, por isso, a UNE se dedicou em politizar o povo por meio da imprensa e de outros mecanismos de comunicação.

Nas páginas do Movimento, a UNE procurou difundir a ideia de que a alfabetização, além de aumentar o número de eleitores, promoveria o “[...] alargamento da visão crítica da realidade social.” (UNE, 1962b, p. 13). Como 


\section{4}

O impresso movimento da UNE...

tarefa politica, para os dirigentes universitários, a alfabetização estava associada ao projeto de transformação social voltado para um desenvolvimento nacional baseado nas forças produtivas industriais, no maior aproveitamento do solo e no controle do capital externo.

Para o pensamento progressista, o projeto de independência econômica do nosso país seria “[...] o resultado do esfôrço, do trabalho, da luta do povo brasileiro, empenhado em construir, com as próprias mãos, uma nação livre e soberana.” (MAGALHÃES et al., 1962, p. 115). Nesse contexto de mobilizações pelo desenvolvimento nacional, a UNE se empenhou nas atividades relacionadas ao campo educacional, além de colaborar em outras frentes democráticas e nacionalistas.

Observamos que, nas matérias publicadas na revista Movimento, o tema do analfabetismo foi abordado a partir da ideologia do desenvolvimento nacional, ou seja, atrelada à luta politica e ideológica travada entre os poderes dominantes e os grupos de renovação, conhecidos na época como progressistas. O analfabetismo foi concebido como um subproduto do latifúndio e do imperialismo e, por isso, esses elementos deveriam ser combatidos prioritariamente pelas camadas populares.

A eliminação das desigualdades sociais, entre elas a desigualdade cultural expressa na carência educacional, depende da eliminação das classes sociais, uma vez que para "[...] educar as crianças, é preciso alimentá-las e liberá-las da necessidade de trabalhar para viver.” (MARX, 1844, p. 7). Embora a UNE tenha considerado o analfabetismo como efeito da base produtiva, acabou optando pela luta política e ideológica por considerar a mais efetiva diante das contradições brasileiras, o que demonstra um comportamento característico da sociedade de classes em que o interesse particular de um grupo prevalece ao interesse universal.

Para a UNE e outros setores progressistas, a alfabetização era fundamental para que os trabalhadores se tornassem sujeitos de decisões políticas, participando especialmente das eleições. Além disso, com os conhecimentos acerca da sociedade e do mundo, os individuos conscientes da dominação que os envolviam e organizados coletivamente poderiam buscar 


\section{5}

Carla Michele Ramos Torres e Maria Isabel Moura Nascimento

meios para se libertarem dessa condição a eles imposta. Outra relevância da instrução educacional dos trabalhadores no contexto econômico brasileiro dos anos iniciais de 1960 era a formação para o desenvolvimento nacional, haja vista que:

[...] no momento em que a técnica passa a ganhar fundamentação científica, o artesão, o agricultor, o operário analfabeto, tem suas chances de progredir tecnicamente, limitadas pelo analfabetismo a sua participação no desenvolvimento econômico do país é reduzida, tanto na elaboração como no proveito. (MEB, 2009, p. 311).

O desenvolvimento econômico do país sob bases nacionais dependia da transformação da estrutura produtiva fortalecida pelo analfabetismo. Portanto, a escolarização dos trabalhadores era um elemento essencial para a expansão do capitalismo industrial, segundo o pensamento progressista da UNE. A entidade universitária chegou a afirmar que o setor industrial, "[...] para quem a educação do operário é fator de desenvolvimento industrial, leva, já neste momento, diversos setores do país a reclamarem contra a carência escolar.” (UNE, 1962b, p. 12, grifo nosso).

A oferta da escolarização em seus mais variados níveis, inclusive o ensino superior, atenderia as demandas dos setores econômicos ligados à indústria nacional e também aos setores socias que avistavam o caminho para o avanço democrático e cultural do país no crescimento econômico. Dessa forma, a educação passou a ter uma função significativa na ideologia do desenvolvimento nacional, disseminado pelos grupos progressistas brasileiros, pois, para esses, o acesso à linguagem escrita e à consciência crítica era uma das frentes de luta do povo brasileiro pela sua libertação.

Mas, ao propor alfabetizar para a libertação, tendo como orientação ideológica o projeto de desenvolvimento econômico nacional de base capitalista, a UNE não conseguiu avançar para um projeto revolucionário que efetivamente pudesse contribuir para erradicar as desigualdades educacionais. Ao preservar o capitalismo, enquanto organização produtiva, mantém-se a divisão social, o antagonismo de classe e a unilateralidade do ensino. Nesse sentido, a luta pela democratização do ensino não significaria 


\section{6}

O impresso movimento da UNE...

que a população alcançaria, na sua totalidade, os niveis mais elevados de ensino e se apropriaria plenamente dos conhecimentos humanos.

Além do mais, o desenvolvimento da grande indústria e a exigência tecnológica da produção permitem uma formação mais técnica e especializada de uma parcela diminuta da sociedade, uma vez que o grande contingente de trabalhadores torna-se um “[...] mero acessório da máquina, do qual se exige apenas o mais simples e monótono movimento da mão, de aprendizado facílimo.” (MARX; ENGELS, 2012, p. 51). Assim, quanto mais avançada for a sociedade capitalista, maior será a apropriação desigual dos conhecimentos humanos.

Sobre a educação da população e o papel do Estado nesse setor, o pai do liberalismo econômico apontou que a "[...] educação das pessoas comuns talvez exija, em uma sociedade civilizada e comercial, mais atenção por parte do Estado que a de pessoas de alguma posição e fortuna.” (SMITH, 1996b, p. 245). Essas pessoas comuns, devido às suas condições financeiras, precisam trabalhar o mais cedo possivel para sobreviverem e suas ocupações são tão simples e cansativas que suas mentes e corpos não conseguem estímulos para outras atividades. Mas, ainda que não possam ter a mesma instrução que as pessoas de melhores condições sociais, os individuos mais pobres:

[...] podem aprender as matérias mais essenciais da educação - ler, escrever e calcular - em idade tão jovem, que a maior parte, mesmo daqueles que precisam ser formados para as ocupações mais humildes, têm tempo para aprendê-las antes de empregar-se em tais ocupações. Com gastos muito pequenos, o Estado pode facilitar, encorajar e até mesmo impor a quase toda a população a necessidade de aprender os pontos mais essenciais da educação. (SMITH, 1996b, p. 246).

Dessa forma, "como modo de evitar a degeneração completa da massa do povo decorrente da divisão do trabalho, A. Smith recomendava o ensino popular, a cargo do Estado, embora em doses cautelosamente homeopáticas." (MARX, 2013, p. 542). No sistema capitalista, portanto, a educação ofertada à classe trabalhadora pelo Estado não tem como propósito a libertação real da estrutura que lhe domina e explora. Ao contrário disso, a instrução é um dispositivo de preservação da ordem produtiva. 


\section{7}

Carla Michele Ramos Torres e Maria Isabel Moura Nascimento

Nesse sentido, a democratização do ensino, almejada pela UNE, no início da década de 1960, estava diretamente ligada ao projeto de desenvolvimento econômico nacional que exigia crescimento do eleitorado, formação de mão de obra tecnicamente especializada para a expansão das forças produtivas e crescimento do mercado interno tanto produtivo quanto consumidor. Apesar disso, acreditamos que os movimentos de educação popular produziram efeitos práticos como, por exemplo, a aproximação entre uma parte da elite intelectual e das classes trabalhadoras e, consequentemente, uma reflexão sobre as possibilidades de superação do subdesenvolvimento brasileiro.

\section{Considerações Finais}

O pensamento é uma síntese de múltiplas determinações, não sendo algo em si, isolado e constituído de abstrações e sim uma expressão das ações humanas no curso de um processo objetivo e contraditório em que há tensões de interesses sociais, mas, ao mesmo tempo, unidade entre os sujeitos coletivos com graus diferentes de consciência. Assim, quando Marx e Engels (2007) nos apontaram que, para examinar a história dos homens, é preciso levar em consideração que a ideologia é apenas uma das faces dessa história, estavam desvelando o caráter material da ideologia, isto é, sua natureza teórica e prática.

A revista Movimento, enquanto expressão ideológica da UNE, procurou ser um canal de comunicação dos setores intelectuais progressistas e, por meio das reportagens e matérias, pudemos conhecer a concepção acerca da educação brasileira da entidade universitária, responsável pela publicação. Nos anos de 1962 e 1963, estava em pauta entre as forças progressistas a ideia de desenvolvimento nacional, que expressava naquele momento histórico o progresso econômico de base capitalista com ênfase na autonomia do mercado, e essa concepção levou a entidade universitária a definir a educação como fator de elevação cultural e, consequentemente, progresso material.

O periódico Movimento teve um papel importante na politização da base estudantil que geralmente não tinha acesso direto às discussões e 


\section{8}

O impresso movimento da UNE...

deliberações dos seminários promovidos pela UNE, bem como suas teorias e ações no campo progressista. No sentido de levar ao estudante a proposta de reforma educacional definida nas assembleias universitárias, o impresso se tornou um mecanismo ideológico com o intuito de sustentar as reivindicações do movimento estudantil.

Como a UNE era a entidade representativa dos estudantes do ensino superior brasileiro, o tema da educação foi abordado nas páginas do Movimento, sendo a alfabetização um dos assuntos mais destacados. Essa questão se tornou uma das principais bandeiras das atividades promovidas pela entidade universitária no âmbito educacional, durante os anos de 1962 e 1963, e, por isso, precisava ser politizada entre os estudantes.

A alfabetização foi concebida pela UNE como sendo de extrema importância para a elevação do nível cultural da sociedade brasileira e, sobretudo, para a ampliação da democracia, uma vez que os analfabetos, naquele momento, não tinham o direito ao voto. A revista Movimento publicou matérias que evidenciavam a defasagem educacional entre as classes trabalhadoras, principalmente entre os trabalhadores do campo que, por estarem subordinados ao sistema latifundiário, sofriam com a carência escolar.

A UNE não acreditava que o congresso político brasileiro, na época, fosse mudar a constituição possibilitando que os analfabetos votassem. Por isso, a entidade universitária defendeu uma campanha de alfabetização em massa sob a vanguarda do movimento estudantil, por vir demonstrando, ao longo de sua existência, um compromisso com as lutas nacionais e democráticas. Como as reformas deveriam ser realizadas pela via pacífica e o Estado seria o promotor de tais transformações, o impresso Movimento difundiu a ideia de que, somente com a participação das massas populares nas eleições, era possivel a construção de um Estado Democrático Popular que, como vimos, foi uma visão contraditória da função estatal no modo de produção capitalista.

As reformas educacionais, disseminadas pela UNE em sua revista, situaram-se no limite do contexto histórico brasileiro naqueles primeiros anos 


\section{9}

de 1960. Sendo os estudantes do ensino superior um pequeno grupo de jovens que alcançavam um nível elevado de escolarização e de conhecimento cultural, acabaram lutando por mudanças que, na prática, não afetaria a totalidade populacional do país, ainda tão distante dos requisitos básicos da escolaridade. Apesar disso, é preciso salientar que as lideranças universitárias se preocuparam com os problemas educacionais brasileiros e se envolveram em campanhas de educação e cultura popular, causa pela qual foram concebidos pelos grupos políticos conservadores como comunistas e nocivos à segurança nacional.

\section{Referências}

ABEND, Aron. O grande país dos analfabetos. Movimento, Rio de Janeiro: Universitária, n. 2, p. 5-7, maio 1962.

BARRETO, Alberto. A liberdade de imprensa. Movimento, Rio de Janeiro: Universitária, n. 8, p. 6-8, fev. 1963b.

BRANDT, Vinícius Caldeira. Depoimento. Movimento, Rio de Janeiro: Universitária, n. 5, p. 26-27, set. 1962.

CABRERA, Luiz Rolando. A situação escolar em Cuba. Movimento, Rio de Janeiro: Universitária, n. 9, p. 41-42, mar. 1963.

CENTRO POPULAR de cultura da União Nacional dos Estudantes - CPC da UNE. Movimento, Rio de Janeiro: Universitária, n. 1, contracapa, mar. 1962.

COMISSÃO A. Atuação dos movimentos de cultura popular e alfabetização nas diferentes Zonas, Regiões e Grupos Sociais. Recife, 1963. In: Primeiro Encontro Nacional de Alfabetização e Cultura Popular. Brasília: Ministério da Educação, Secretaria de Educação Continuada, Alfabetização e Diversidade, UNESCO, 2009. p. 283-286.

EDITORIAL. Movimento, Rio de Janeiro: Universitária, n. 1, p. 3, mar. 1962.

INSTITUTO BRASILEIRO DE GEOGRAFIA E ESTATÍSTICA - IBGE. Anuário estatístico do Brasil - 1955. Rio de Janeiro. Rio de Janeiro: Diretoria de Comunicação e Divulgação, $1955 . \quad$ Disponivel em: <https://servicodados.ibge.gov.br/Download/Download.ashx?http=1\&u=bib lioteca.ibge.gov.br/visualizacao/periodicos/20/aeb_1955.pdf>. Acesso em: 02 out. 2018. 


\section{0}

O impresso movimento da UNE...

INSTITUTO BRASILEIRO DE GEOGRAFIA E ESTATÍSTICA - IBGE. Anuário estatístico do Brasil - 1962. Rio de Janeiro: Diretoria de Comunicação e Divulgação, $1962 . \quad$ Disponivel em: <https://biblioteca.ibge.gov.br/visualizacao/periodicos/20/aeb_1962.pdf>. Acesso em: 19 abr. 2018.

INSTITUTO NACIONAL DE ESTUDOS E PESQUISAS EDUCACIONAIS ANÍSIO TEIXEIRA - INEP. Mapa do analfabetismo no Brasil. [200?] Disponivel em: <http:/ / portal.inep.gov.br/documents / 186968/485745/Mapa+do+analfabet ismo+no+Brasil/a53ac9ee-c0c0-4727-b216-035c65c45e1b?version=1.3>.

Acesso em: 01 maio 2018.

LOCKE, John. Segundo tratado do governo civil. Tradução de Magda Lopes e Marisa Lobo da Costa. [Petrópolis]: Vozes, Clube do Livro Liberal, [20--]. Disponivel em: <http://www.xr.pro.br/if/lockesegundo_tratado_sobre_o_governo.pdf>. Acesso em: 02 abr. 2018.

LOMBARDI, José Claudinei. Educação e nacional-desenvolvimentismo: articulações e confrontos entre concepções e pedagogias antagônicas (19461964). Revista HISTEDBR On-line, Campinas, n. 67, p. 23-38, mar. 2016.

MAGALHÃES, Sérgio et al. A questão da remessa de lucros. Rio de Janeiro: Universitária, 1962. Coleção Cadernos Políticos 1.

MARX, Karl. O Capital: crítica da economia política. Livro I: O processo de produção do capital. Tradução de Rubens Enderle. São Paulo: Boitempo, 2013.

MARX, Karl. Glosas criticas marginais ao artigo "O rei da Prússia e a reforma social". De um prussiano. 1844. Tradução de Ivo Tonet. Disponivel em: <http:/ /www.dominiopublico.gov.br/download/texto/ma000012.pdf>. Acesso em: 11 out. 2017.

MARX, Karl; ENGELS, Friedrich. A ideologia alemã. Tradução de Rubens Enderle; Nélio Schneider; Luciano Cavini Martorano. São Paulo: Boitempo, 2007.

MARX, Karl; ENGELS, Friedrich. Manifesto do partido comunista. Tradução de Sergio Tellaroli. São Paulo: Penguin Classics/Companhia das Letras, 2012.

MOVIMENTO. $1^{\circ}$ Seminário de imprensa. Movimento, Rio de Janeiro: Universitária, n. 3, p. 2, jun. 1962.

MOVIMENTO DE EDUCAÇÃO DE BASE - MEB. Comissão de estudos sobre alfabetização. Recife, 1963. In: Primeiro Encontro Nacional de Alfabetização e Cultura Popular. Brasília: Ministério da Educação, Secretaria de Educação Continuada, Alfabetização e Diversidade, UNESCO, 2009. p. 311-316. 


\section{1}

PRADO JÚNIOR, Caio. História econômica do Brasil. 26. ed. São Paulo: Brasiliense, 1981.

SAVIANI, Dermeval. História das ideias pedagógicas no Brasil. Campinas, SP: Autores Associados, 2007. Coleção memória da educação.

SHIROMA, Eneida Oto; MORAES, Maria Célia Marcondes de; EVANGELISTA, Olinda. Política Educacional. Rio de Janeiro: DP\&A, 2000.

SILVA, Lucíola Lima; CASTRO, Paulo Furtado de; GUIMARÃES, César. Hora e vez da boa escolha. Movimento, Rio de Janeiro: Universitária, n. 6, p. 3-7, out. 1962.

SMITH, Adam. A riqueza das nações: investigação sobre sua natureza e suas causas. Tradução de Luiz João Baraúna. Os Economistas. São Paulo: Nova Cultural, 1996. Disponivel em: <http://portalconservador.com/livros/AdamSmith-A-Riqueza-das-Nacoes.pdf>. Acesso em: 12 fev. 2018. Vol. II.

SODRÉ, Nelson Werneck. Introdução à revolução brasileira. Rio de Janeiro: Civilização Brasileira, 1963.

UNIÃO NACIONAL DOS ESTUDANTES - UNE. Planificação e descentralização do ensino. Movimento, Rio de Janeiro: Universitária, n. 4, p. 3-4, jul. 1962a.

UNIÃO NACIONAL DOS ESTUDANTES - UNE. Realidade do analfabetismo no Brasil. Movimento, Rio de Janeiro: Universitária, n. 4, p. 12-13, jul. 1962b.

VIEIRA PINTO, Álvaro. Consciência e realidade nacional. Rio de Janeiro: Instituto Superior de Estudos Brasileiros, 1960. Coleção Textos Brasileiros de Filosofia, V. I.

VIEIRA PINTO, Álvaro. Ideologia e desenvolvimento nacional. 2. ed. Rio de Janeiro: ISEB, 1959. 